\title{
Predictors of post-traumatic pituitary failure during long-term follow-up
}

\author{
Orsolya Nemes, ${ }^{1}$ Noemi Kovacs, ${ }^{2}$ Endre Czeiter, ${ }^{2}$ Peter Kenyeres, ${ }^{1}$ Zita Tarjanyi, ${ }^{1}$ \\ Laszlo Bajnok, ${ }^{1}$ Andras Buki, ${ }^{2}$ Tamas Doczi, ${ }^{2}$ Emese Mezosi ${ }^{1}$
}

${ }^{1}$ It $^{\text {st }}$ Department of Internal Medicine, ${ }^{2}$ Department of Neurosurgery; University of Pecs, Hungary

\begin{abstract}
OBJECTIVE: There is increasing awareness among physicians of the risks of traumatic brain injury (TBI)-induced hypopituitarism. We have assessed the prevalence and risk factors of posttraumatic hypopituitarism by analyzing the TBI database of the University of Pecs. DESIGN: This consecutive analysis of 126 TBI survivors (mean age: $\mathbf{4 2 . 4}$ years, average follow-up time: 48 months) revealed that $60.3 \%$ had severe and $39.7 \%$ moderately severe trauma based on GCS score. Subdural hemorrhage $(\mathbf{2 9 . 3 \% )}$ ) and diffuse injury $(27 \%)$ were the most common types of injury; $17.5 \%$ of patients suffered basal skull fractures. RESULTS: The prevalence of major anterior pituitary failure was $\mathbf{5 7 . 1 \%}$. Occurrence of total and partial growth hormone deficiency (GHD/GHI) was 39.7\%, while LH/FSH, TSH and ACTH deficiencies were less frequent, namely 23.0\%, 16.7\% and $10.3 \%$, respectively. Of the 82 patients with multiple endocrine evaluations, $31.7 \%$ presented significant changes in hormonal deficiencies during the follow-up period: new hormone deficiencies developed in 16 patients, while hormonal disturbances resolved in 10 subjects. Looking for factors influencing the prevalence of pituitary dysfunction, endocrine results were analyzed in relation to age, gender, GCS scores, injury types, basal skull fracture, ventricular drain insertion and necessity of neurosurgical intervention. All hormonal disturbances were more prevalent after severe trauma $(\mathrm{OR}: 3.25, p=0.002)$, while the need for surgery proved to be an independent determinant of multiple and GH deficits $(O R: 3.72(p=0.004)$ and $9.33(p=0.001)$ ). CONCLUSION: Post-traumatic hypopituitarism is common and may evolve or resolve over time. Victims of severe TBI and/or patients who have undergone neurosurgical intervention for head injury are the most prone to post-traumatic hypopituitarism.
\end{abstract}

Key words: Traumatic brain injury, Hypopituitarism, GCS, Growth hormone deficiency

Address for correspondence:

Emese Mezosi M.D. Ph.D., Ist Department of Internal Medicine, University of Pecs, 13 Ifjusag, Pecs, H-7624, Hungary;

Tel.: 36-30-565-4155, Fax: 36-72-536-148,

E-mail: emese.mezosi@aok.pte.hu

Received:12-06-14, Accepted: 12-09-14

\section{INTRODUCTION}

Traumatic brain injury (TBI) is a major public health problem with an overall incidence of 235/100,000 persons per year and the leading cause of death and disability in young adults. ${ }^{1}$ The severity of TBI can be measured according to the 15-point 
Glasgow Coma Scale (GCS). ${ }^{2}$ TBI-induced hypopituitarism was first reported in 1918 and until 2000 it was considered as a rare cause of pituitary dysfunction. However, in 2000, Benvenga et al suggested an association between TBI and pituitary failure. ${ }^{3}$ The pathogenesis of TBI-induced hypopituitarism is still not completely understood, but the anatomy of the pituitary gland points to theories based on disturbances in blood supply. ${ }^{4}$ In more than $70 \%$ of the autopsies of patients with fatal TBI, pituitary hemorrhagic infarctions were present and in $40 \%$ of the cases hypothalamic microhemorrhages were also detected..$^{4-6}$ Recently, the role of elevated inflammatory substances (amino acids, nitric oxide, free radicals, interleukin 6) in response to hypoxemia and elevated intracranial pressure (ICP) have emerged as a pathomechanism of secondary brain injury. ${ }^{7-10}$

In the last few years, a number of systematic studies have reported that hypopituitarism is a common sequela of both TBI and subarachnoidal hemorrhage (SAH). ${ }^{7,811-22}$ In a systematic review in 2007, Schneider et al. analyzed 19 clinical studies involving 1137 patients reporting on pituitary function after TBI or $\mathrm{SAH}$. In the chronic phase a $27.5 \%$ prevalence of pituitary dysfunction was found in general. ${ }^{22}$ However, post-TBI hypopituitarism was more common in patients with severe head injury than in those with mild to moderate ones. Previous cohort studies indicated that the somatotroph and gonadotroph axes are the most vulnerable to the impacts of moderate and severe TBI, with deficiency rates averaging $16 \%$ and $14 \%$, respectively. Corticotroph, thyrotroph and posterior pituitary deficiencies are less common, with rates averaging $8 \%, 5 \%$ and $2 \%$, respectively. ${ }^{8}$ Variations in overall prevalence of pituitary dysfunction among different studies can result from different methods of endocrine testing and patient selection.

Literature data concerning the risk factors of pituitary dysfunction after TBI are controversial. Some previous studies failed to show a definitive relationship between injury factors and hypopituitarism. ${ }^{7,14-17,21} \mathrm{On}$ the other hand, according to Kelly et al. the severity of brain injury on acute CT is the strongest predictor of subsequent pituitary dysfunction. ${ }^{11}$ Increased intracranial pressure was also reported to predict post-traumatic hypopituitarism. ${ }^{18}$ In another study, diffuse axonal injury and basal skull fracture were found to be risk factors for post-TBI hypopituitarism. ${ }^{23}$ Pituitary magnetic resonance imaging or $\mathrm{CT}$ scans were abnormal in $80 \%$ of TBI patients with hypopituitarism, compared with $29 \%$ of TBI patients without pituitary dysfunction. ${ }^{24}$ Nevertheless, other studies have found new endocrinopathies even after milder TBI, indicating that severe head trauma might not be an essential factor for the development of post-TBI pituitary failure. ${ }^{3,13}$

Pituitary dysfunction can be acute or may develop over a period of up to 10 years post-injury and some of the deficits can be transitory. The etiology of such a fluctuation of pituitary function is unclear, but it is suspected that the ongoing atrophy of the injured pituitary gland and infundibular structures may be responsible for it. In $70 \%$ of the patients, hypopituitarism presents within the $1^{\text {st }}$ year after TBI. ${ }^{10}$ Recovery of pituitary function can occur in up to $50 \%$ of patients with major hormonal deficiencies diagnosed at 3 months post-injury. ${ }^{25,26}$

As regular endocrine follow-up of every patient with TBI of various severities is unrealistic, identification of predisposed patients is of great importance. The aim of our study was to evaluate the long-term prevalence of post-traumatic hypopituitarism in relation to the known and potential risk factors for the development of hormonal deficits.

\section{SUBJECTS AND METHODS}

Patients available for endocrine follow-up had suffered TBI between 2003 and 2013. Data were collected regarding the type and severity of brain injury, as well as on endocrine function and clinical and radiological parameters, using the joint database of the Department of Neurosurgery and the $\mathrm{I}^{\mathrm{st}}$ Department of Internal Medicine, Endocrine Division, University of Pecs, Hungary. Either endocrine evaluation was part of the routine neurosurgical follow-up or patients were asked by letter to participate in the endocrine screening. Of the 86 survivals of 413 severe head trauma patients treated at this one center during a 10 -year period, 76 had endocrine test results. Fifty of the 392 moderate head trauma patients treated between 2007 and 2012 responded to the invitation to participate in our study. The study was carried out 
in accordance with the Declaration of Helsinki (2003) of the World Medical Association and approved by the Ethics Committee at the Medical Center of the University of Pecs. Subjects participated in the study after their written informed consent had been obtained.

Post-TBI pituitary functions were evaluated in 126 patients: 103 men and 23 women. Nine patients were younger than 18 years at the time of brain trauma, the youngest being 11 and the oldest 89 years old. Their mean age at the time of brain injury was 42.4 years (men: 42.3 years, women: 43.0 years, NS).

The severity of brain injury was determined according to the most severe Glasgow Coma Scale (GCS) score during neurosurgical hospitalization and intensive care. This classification was chosen because on-admission high GCS scores deteriorate significantly in many patients, representing more severe brain injury. Based on this, patients were divided into a severe (lowest GCS score $\leq 8$ ) and a moderate (GCS score 9-12) head trauma group.

According to this classification, 76 patients had severe and 50 patients had moderately severe brain injury. Neurosurgical intervention was performed in 68 subjects, also including external ventricular drainage (EVD) in 38 patients. In 25 cases exclusively EVD was applied. Intensive care without surgical intervention was sufficient in 33 patients.

In order to determine possible risk factors for post TBI hypopituitarism, CT and/or MRI findings during the acute phase of neurosurgical intensive care were also assessed. Primarily focal brain injury was present in 87 cases, while 39 patients suffered predominantly diffuse brain injury. The leading diagnoses according to the imaging procedures were: subdural hemorrhage (SDH): 37 patients; intracranial hemorrhage (ICH): 27 patients; SDH + ICH: 12 cases; epidural hemorrhage (EDH): 16 patients; diffuse injury (DIFF): 34 patients. In 22 cases base skull fracture was also diagnosed. Baseline characteristics of all patients are displayed in Table 1.

The first endocrine evaluation after TBI varied between 1 month and 5.75 years (average 2.0 years). Multiple blood tests were performed in 82 patients; their average endocrine follow-up period was 3 years. The mean $\pm S D$ of follow-up time after TBI was $3.98 \pm 2.54$ years. To consider the differences in data quality, we divided our patients into three groups according to the completeness of endocrine data: group A (n:44): subjects with single basal hormone (free FT4, TSH, testosterone, ACTH, cortisol, GH, IGF1) results; group B (n:48): subjects with stimulation tests for GH and/or ACTH axes in ad-

Table 1. Baseline characteristics

\begin{tabular}{|c|c|c|c|c|c|c|c|}
\hline & & $\mathbf{N}$ & $\%$ & Mean & SD & Min & Max \\
\hline Age (y) & & 126 & 100 & 42.40 & 18.67 & 11 & 89 \\
\hline \multirow[t]{2}{*}{ Gender } & M & 103 & 82 & & & & \\
\hline & $\mathrm{F}$ & 23 & 18 & & & & \\
\hline First endocrine evaluation (y) & & 126 & 100 & 2.04 & 1.49 & 0.08 & 5.75 \\
\hline Number of blood tests & & & & 3.38 & 1.76 & 1 & 7 \\
\hline Follow-up time after TBI (y) & & 126 & 100 & 3.98 & 2.54 & 0.08 & 10.25 \\
\hline Endocrine follow-up time (y) & & 82 & 65 & 2.99 & 2.66 & 0.17 & 8.50 \\
\hline Severe head trauma & & 76 & 60 & & & & \\
\hline Moderate head trauma & & 50 & 40 & & & & \\
\hline Neurosurgery & & 68 & 54 & & & & \\
\hline Ventricular drain insertion & & 63 & 50 & & & & \\
\hline Non-invasive care & & 33 & 26 & & & & \\
\hline Focal injury & & 87 & 69 & & & & \\
\hline Diffuse injury & & 39 & 31 & & & & \\
\hline
\end{tabular}

$\mathrm{N}$ : number of available data for each parameter; SD: standard deviation; y: year. 
dition to basal hormone measurements; group $\mathrm{C}$ (n:34): subjects with multiple basal hormone tests. In optimal circumstances stimulation tests would have been done more frequently but a number of patients in group A were lost to follow-up. If other pituitary failure was evident from basal hormone results, one stimulation test was used to diagnose GHD (ITT in 25 cases, glucagon test in 14 cases and arginine test in 1 case). Two GH stimulation tests were required in 8 patients as $\mathrm{GH}$ production was the only affected pituitary axis: in 5 patients arginine and glucagon tests, in 2 cases ITT and glucagon tests and in 1 case ITT and arginine tests were carried out.

\section{Biochemical assays}

All hormone levels were measured at the Department of Laboratory Medicine, University of Pecs, as part of the routine follow-up protocol, defined in the Hungarian College of Neurosurgeons Guideline for the Treatment of Severe Head Injury. Serum TSH and free T4, cortisol, LH and FSH and testosterone concentrations were determined using Cobas, Roche Diagnostic. Plasma ACTH and GH concentrations were measured using Immulite/Immulite 1000 ACTH and Growth Hormone (Siemens) solid phase, two-site sequential chemiluminescent immunometric assays. Serum IGF-I concentration was determined using Immulite (DPC), an automated chemiluminescent assay system, throughout the study period.

\section{Definitions of hormonal dysfunctions used in the study}

Thyroid-stimulating hormone (TSH) deficiency: Free thyroxin (fT4) $<12 \mathrm{pmol} / \mathrm{L}(0.93 \mathrm{ng} / \mathrm{dl})$ and $\mathrm{TSH} \leq 2.5 \mathrm{U} / \mathrm{L}$, no previous medical history of thyroid disease before TBI.

Adrenocorticotropic hormone (ACTH) deficiency: Peak cortisol in stimulation test $<500 \mathrm{nmol} / \mathrm{L}$ (18 $\mathrm{ug} / \mathrm{dl}$ ) or basal cortisol $<100 \mathrm{nmol} / \mathrm{L}(3.6 \mathrm{ug} / \mathrm{dl})$ if no stimulation test was performed. For assessment of the ACTH axis we used the insulin tolerance test (ITT) and glucagon test, all with a cortisol cut-off $<500 \mathrm{nmol} / \mathrm{L}$ (18 ug/dl).

Luteinizing hormone ( $\mathrm{LH}$ )/follicle stimulating hormone (FSH) deficiency in men: Testosterone level $<9.9 \mathrm{nmol} / \mathrm{L}(2.85 \mathrm{ng} / \mathrm{ml})$ and $\mathrm{LH} \leq 8.6 \mathrm{U} / \mathrm{L}$ and/or $\mathrm{FSH} \leq 12.4 \mathrm{U} / \mathrm{L}$.
Luteinizing hormone ( $\mathrm{LH})$ /follicle stimulating hormone (FSH) deficiency in women $<50$ years of age: Amenorrhea and/or $\mathrm{LH} \leq 1.7 \mathrm{U} / \mathrm{L}$ and $\mathrm{FSH} \leq 1.5 \mathrm{U} / \mathrm{L}$.

Luteinizing hormone ( $\mathrm{LH}$ )/follicle stimulating hormone $(\mathrm{FSH})$ deficiency in women $>50$ years of age: $\mathrm{LH} \leq 15 \mathrm{U} / \mathrm{L}$ and/or FSH: $\leq 15 \mathrm{U} / \mathrm{L}$.

Growth hormone deficiency (GHD): Peak GH below the cut-off in the stimulation test. For assessment of the GH axis we applied ITT and glucagon tests using a GH cut-off $<3 \mathrm{ng} / \mathrm{ml}$. GH results in ITT were evaluated when blood glucose was $<2.2 \mathrm{mmol} / \mathrm{L}$ $(39.6 \mathrm{mg} / \mathrm{dl})$. In the arginine tests $\mathrm{GH}$ cut-off 4-11 $\mathrm{ng} / \mathrm{ml}$ was used, depending on the BMI.

Growth hormone insufficiency (GHI): Insulin-like growth factor-I (IGF-I) levels below the local ageand sex-specific reference value (IGF-I SDS <-2.00) and stimulation test not possible or peak GH levels between 3 and $10 \mathrm{ng} / \mathrm{ml}$ in ITT/glucagon tests. ${ }^{27}$ All the available data were evaluated individually when patients were assigned to this category.

The utilization of this category is rather controversial as the cut-off value for GHD ( $3 \mathrm{ng} / \mathrm{ml})$ is arbitrary and a number of studies have suggested the use of higher cut-off values based on ROC analysis (for ITT it was found to be $5.62 \mathrm{ng} / \mathrm{ml}$ ). ${ }^{28}$ Like many other biological parameters, the impairment of GH secretion forms a continuous variable. Patients with borderline response in the stimulation tests may have symptoms of GHD. ${ }^{29}$

\section{Statistical analysis}

Statistical analyses were performed employing SPSS 22.0 software (SPSS, Inc., Chicago, IL, USA). Descriptive statistics of quantitative variables with normal distribution are expressed as mean \pm standard deviation (SD). Relationships between binomial variables were tested using the chi-square and Fischer's exact tests as appropriate. Level of significance during multiple comparisons was corrected according to the Benjamini-Hochberg method. Quantitative variables of subgroups were compared using Student's t-test. Relationships between quantitative variables were evaluated with bivariate correlation. To identify the determinants of pituitary failure, multiple and single hormone deficiencies and new hormonal disturbances, binary logistic regression analysis using backward 
method was performed. Values of $P<0.05$ were considered statistically significant.

\section{RESULTS}

\section{Prevalence of pituitary dysfunction}

The prevalence of any major anterior pituitary hormone deficiency among the 126 patients was $57.1 \%$ (Figure 1). GHD/GHI was the most frequent (39.7\%) abnormality, followed by secondary hypogonadism (23\%), while secondary hypothyroidism and ACTH deficiency were diagnosed in 16.7 and $10.3 \%$ of all TBI patients, respectively. Of the investigated men $28.2 \%$ exhibited secondary hypogonadism but no affected women were detected. In $56.9 \%$ of the cases with hormone deficiency only one pituitary axis was affected. Two patients developed complete anterior pituitary insufficiency in which all four hormonal axes were impaired (Figure 2). Not only was there identification of GHD/GHI as an isolated deficiency, but twenty other isolated failures $(9 \mathrm{TSH}, 9 \mathrm{FSH} / \mathrm{LH}$ and $2 \mathrm{ACTH}$ ) were also detected. The prevalence of single or multiple hypopituitarisms in subgroups A, B and C is shown in Figure 3. Multiple pituitary dysfunction was found most frequently $(52.1 \%)$ in those patients who also had stimulation tests (group B), while single deficiency was diagnosed in patients with basal endocrine evaluations $(34.1 \%$ in group A, $41.2 \%$ in group C). Although a selection bias definitely affected the comparisons of these groups, since

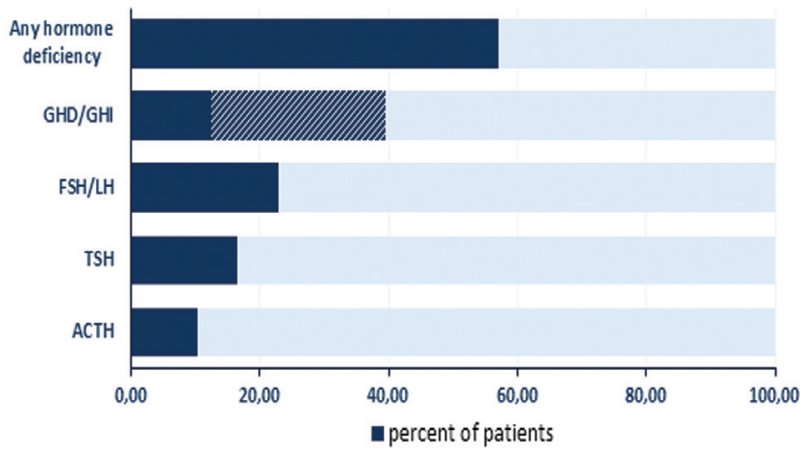

Figure 1. Prevalence of anterior pituitary hormone deficiencies in 126 survivors of severe or moderate TBI. GHD: growth hormone deficiency, GHI: growth hormone insufficiency, FSH: follicle stimulating hormone, LH: luteinizing hormone, TSH: thyroid-stimulating hormone, ACTH: adrenocorticotropic hormone. stimulation tests were more frequently conducted in patients with abnormal basal hormone measurements, basal hormone measurements were sufficient to assess the thyroid and gonadal axes (stimulation tests would be required only for the evaluation of $\mathrm{GH}$ and ACTH productions).

In our GHI patient population $(n=31)$ multiple hormone deficits were detected in 14 cases. The IGFI SDS values were significantly lower (mean \pm SD: $-2.96 \pm 1.72, \mathrm{p}<0.001)$ than in patients without impaired GH secretion (mean \pm SD: $-1.14 \pm 1.55$ ) and were not

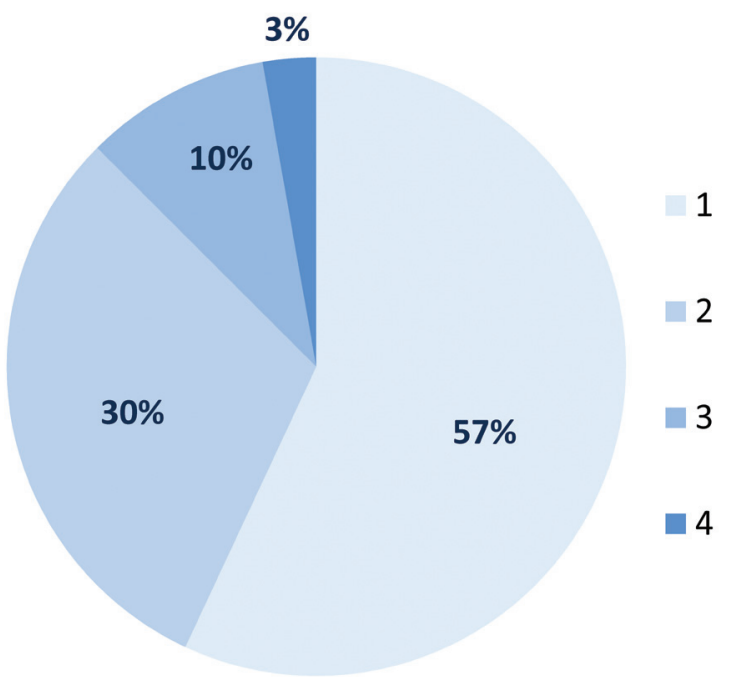

Figure 2. Distribution of pituitary hormone dysfunction in $\%$ by the number of hormonal axes in 72 TBI patients.

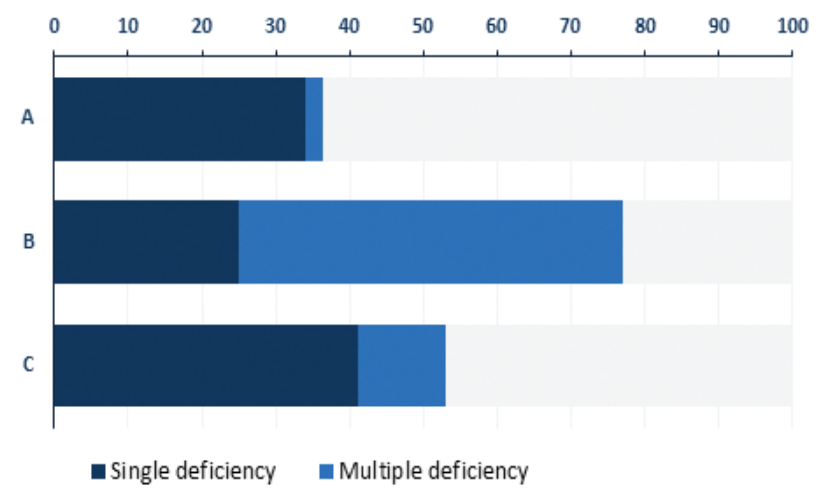

Figure 3. Prevalence of single and multiple pituitary deficiencies in $\%$ by different definitions. A: patients with single basal hormone measurement. B: patients with basal hormone results and stimulation tests. C: patients with multiple basal hormone measurements. 
different from those of the GHD group (mean \pm SD: $-2.50 \pm 1.48, p=0.35$ ). Stimulation tests were possible in 13 subjects and the mean GH peak was $7.04 \mathrm{ng} /$ ml (min: $3.36 \mathrm{ng} / \mathrm{ml}$, max: $9.4 \mathrm{ng} / \mathrm{ml}$ ).

Subdural hemorrhage $(n=37)$ and diffuse injury $(n=34)$ were the most common injury types; 22 patients suffered basal skull fractures as well. The prevalence of brain injury types with or without hormonal deficiencies is summarized in Table 2. No statistically significant association was established between the type of injury and pituitary malfunction.

Of the 82 patients with multiple endocrine evaluations, $31.7 \%$ presented changes in major hormonal deficiencies during the follow-up period. Sixteen patients had new hormone deficiencies in the course of an average follow-up period of 44 months (GHD/ GHI: 3/5, LH/FSH: 9, ACTH: 5, TSH: 2), while 10 subjects' hormone deficiencies resolved during the average follow-up period of 52 months (GHI: 1, LH/ FSH: 4, TSH: 4, ACTH: 1) (Table 3).

\section{Possible risk factors associated with hypopituitarism}

Concerning the possible risk factors for the development of post-traumatic pituitary dysfunction, the prevalence of hormone deficiencies was analyzed in relation to age, gender, GCS scores, injury types, basal skull fracture, ventricular drain insertion and

Table 2. Brain injury types in patients with or without major hormonal deficiencies. The patients with different types of brain injuries, based on CT findings are categorized as pituitary deficient or not. Percentages are compared using the Fischer's exact test

\begin{tabular}{|c|c|c|c|}
\hline \multirow[t]{2}{*}{ CT findings } & \multicolumn{2}{|c|}{$\begin{array}{c}\text { Hormone } \\
\text { deficiency }(\%)\end{array}$} & \multirow{2}{*}{$\begin{array}{c}\text { Fischer } \\
\mathbf{p} \\
\text { value }\end{array}$} \\
\hline & yes & no & \\
\hline $\begin{array}{l}\text { Subdural hematoma } \\
\text { (SDH) }\end{array}$ & $21(29.2)$ & $16(29.6)$ & 0.555 \\
\hline $\begin{array}{l}\text { Intracranial hemorrhage } \\
(\mathrm{ICH})\end{array}$ & $14(19.4)$ & $11(20.4)$ & 0.536 \\
\hline $\mathrm{SDH}+\mathrm{ICH}$ & $7(9.5)$ & $5(9.6)$ & 0.591 \\
\hline Epidural hemorrhage & $11(15.3)$ & $5(9.3)$ & 0.234 \\
\hline Diffuse injury & $19(26.4)$ & $15(27.8)$ & 0.510 \\
\hline Basal skull fracture & $10(13.9)$ & $12(22.2)$ & 0.163 \\
\hline Overall & 72 & 54 & \\
\hline
\end{tabular}

Table 3. Changes in major hormonal deficiencies in 82 patients with multiple endocrine evaluations in the acute phase $(<1$ year post TBI) and in the chronic phase ( $>1$ year post TBI)

\begin{tabular}{ccc}
\hline $\begin{array}{c}\text { N of deficient } \\
\text { hormonal axes }\end{array}$ & $\begin{array}{c}\text { N of patients } \\
\text { at the first } \\
\text { evaluation }\end{array}$ & $\begin{array}{c}\text { N of patients during } \\
\text { the endocrine } \\
\text { follow-up }\end{array}$ \\
\hline 0 & 38 & 31 \\
1 & 23 & 25 \\
2 & 16 & 19 \\
3 & 4 & 5 \\
4 & 1 & 2 \\
\hline
\end{tabular}

requirement for neurosurgery. GHD+GHI were more frequent in patients with severe brain injury, ventricular drain insertion and neurosurgery. Odds ratios for the development of GHD+GHI are the following: 2.7 for severe versus moderate injury $(\mathrm{p}=0.011), 2.58$ for EVD insertion $(\mathrm{p}=0.011)$ and 3.53 for neurosurgery $(\mathrm{p}=0.001)$. GHD was markedly associated with surgical intervention (OR: 9.33, $\mathrm{p}=0.001)$. Male gender predisposed to $\mathrm{FSH} / \mathrm{LH}$ deficit (OR: 9.01, $\mathrm{p}=0.004$ ). Multiple hormone deficiencies correlated to the requirement for neurosurgery (OR: $3.72, p=0.004)$. All hormonal disturbances were more prevalent after severe head trauma and ventricular drain insertion, with odds ratios $3.25(\mathrm{p}=0.002)$ and $2.52(\mathrm{p}=0.012)$, respectively.

The aforementioned factors were included in a backward binary logistic regression model to test for independent determinants of hypopituitarism. The individual and combined hormone deficiencies and the changes during follow-up time were analyzed separately. Hormonal disturbances detected at the first investigation were determined by the severity of trauma $(p=0.033)$ and by focal injury $(p=0.033)$. At the end of follow-up only the severity of TBI remained an independent predictor $(p=0.003)$. None of the investigated factors related to the development of new hormonal failures. Multiple hormonal deficiencies $(p=0.019)$, GHD + GHI $(p=0.013)$ and GHD $(p=0.004)$ were all influenced by the requirement for surgical intervention, while the GHD+GHI subgroup was associated with ventricular drain insertion $(\mathrm{p}=0.012)$ too. No independent predictors were identified for the evolution of FSH/LH, TSH and ACTH deficiency. 


\section{DISCUSSION}

Although the occurrence of post-traumatic hypopituitarism is well known and has been intensively investigated over the last decade, many questions arise in the routine management of these patients. Brain trauma is very common and to perform endocrine investigations in every case is almost impossible. ${ }^{30}$ Further debated topics are the optimal time of the first investigation given the dynamic changes of the endocrine failures and the need for repeated evaluations. To find a consensus in this field is further inhibited by the multifaceted nature of pituitary malfunction: while ACTH deficiency and complete pituitary failure might be a life-threatening condition mandating immediate detection and intervention, in the most frequent form of isolated GH deficiency which negatively influences the quality of life and may increase cardiovascular mortality in the long term - the diagnosis could be delayed for as long as one year after TBI without major consequences. ${ }^{31,32}$

In this study, pituitary function and possible risk factors for hypopituitarism were assessed along with long-term follow-up and multiple endocrine evaluations in a large post-traumatic patient population. Some degree of pituitary dysfunction was found in the majority of our TBI patients with previous moderate to severe injury (57.1\%). This high prevalence decreased to $42.9 \%$ if patients with partial GH deficiency (GHI) were excluded. Until now, repeated hormonal testing data beyond the 12-month post-injury time point were scarce in the literature and most deficits diagnosed during the first year after TBI were considered to be lasting. ${ }^{11}$ The greatest novelty of our analysis is that we were able to demonstrate considerable variability of the state of the endocrine system during a longitudinal follow-up. Beyond the first year of TBI, $31.7 \%$ of the investigated subpopulation exhibited significant changes in at least one hormonal axis of pituitary function: $19.5 \%$ presented new hormone deficiencies, while in $12.2 \%$ hormone dysfunctions resolved in the later phase.

In accordance with previous reports, the somatotropin and gonadotropin axes proved to be the most vulnerable after TBI with incidences of $39.7 \%$ and $23.0 \% .^{9,33}$ Isolated deficiencies were the most frequent, but it is of note that $43.1 \%$ of the affected patients had multiple pituitary hormone deficiencies, and even moderate head trauma could result in complete pituitary failure. Although ACTH deficiency affected only approximately $10 \%$ of TBI patients, considering the incidence of TBI and the potential life-threatening consequences of secondary adrenal failure it is of outstanding importance to actively search for these patients and to treat them adequately, since determination of risk factors for the development of pituitary failure in this population would substantially aid disease management. It is generally accepted that hypopituitarism is more prevalent after severe brain injury as compared to mild and moderate trauma. ${ }^{15}$ Increased intracranial pressure, diffuse axonal injury, basal skull fracture and severe acute CT abnormalities were reported in previous studies as predictors of pituitary failure. ${ }^{23,24}$ Indeed, in the present study, the severity of brain injury also proved to be an independent determinant of all hormonal deficiencies. Hormonal deficits at the first investigation were more prevalent in those patients who suffered focal injury compared to diffuse abnormality on CT scan, but during the follow-up only the severity of trauma remained a decisive factor. Beyond this, in contrast to other reports, ${ }^{10,24}$ we could not identify a statistically significant relationship between hormonal failures and types of brain injury or presence of basal skull fracture, even in this large patient population. To the best of our knowledge, ours is the first study in which hormonal deficits (namely the multiple ones, GHD and GHD+GHI) were markedly associated with surgical intervention: the odds ratio for GHD was 9.33 in patients who would undergo surgery compared to those who did not require this. The prevalence of impaired $\mathrm{GH}$ secretion (GHD+GHI) was also influenced by EVD insertion. Based on this strong relationship, a pathogenic role of increased intracranial pressure in the impairment of GH secretion can be presumed. ${ }^{18}$ Dysfunction of other pituitary axes was not dependent on surgery and no other predictive factor was identified. It is possible that the $\mathrm{GH}$ axis is the most sensitive to the increased ICP, but other explanations cannot be excluded either. The damage of the pituitary gland during the trauma may be multifactorial and these partly unknown factors may play a variety of roles in the impairment of pituitary axes. It is conceivable that the pathogenesis of GHD, $\mathrm{FSH} / \mathrm{LH}, \mathrm{TSH}$ and ACTH deficiency is not neces- 
sarily the same. In our database, there was not only identification of GHD/GHI as an isolated deficiency, but twenty other isolated failures (9 TSH, $9 \mathrm{FSH} / \mathrm{LH}$ and $2 \mathrm{ACTH}$ ) were also detected. However, in order to explain the long-term consequences of TBI, not only the injury itself but the regenerative capacity of the affected individual may need to be taken into consideration.

The circumstances of brain trauma and the manner of intervention may explain the onset of hypopituitarism in the acute phase, but they do not help to understand the development of endocrine abnormalities many years after the trauma. Ongoing atrophy of the sellar and perisellar structures, hypothalamic dysfunction and the role of autoimmunity and genetic polymorphism in the apolipoprotein E gene have been proposed as potential mechanisms underlying the hormonal deficiencies of delayed onset. ${ }^{34-37}$ In accordance with these theoretical considerations, the parameters we were able to investigate were not predictive for the development of new hormonal abnormalities during long-term endocrine follow-up. An important limitation of this study is the heterogeneity of endocrine evaluations. Despite our every effort, a considerable number of the patients were lost to follow-up. This is related to their poor compliance due to frequent major cognitive, physical and psychological deficits and/or deviant behaviors, which typically create a longstanding problem in such investigations. ${ }^{38}$ Furthermore, the prevalence of hypopituitarism with involvement of multiple hormonal axes was highest among patients who underwent endocrine stimulation tests. Also, when patients were repeatedly evaluated during follow-up by basal hormone measurements, the diagnosis of pituitary dysfunction was more frequent. A selection bias in the comparison of these groups also needs to be mentioned, since stimulation tests were more frequently done in patients with abnormal basal hormone measurements. However, a significant proportion of patients in group A with single endocrine evaluation would have required further investigations. Although the investigated population was not particularly large, it is among the largest published from a single center.

In summary, our data confirm that hypopituitarism due to TBI is common, especially in severe cases. It seems that neurosurgical intervention is an independent risk factor. Acute circumstances can influence the development of early pituitary dysfunctions, but they are usually not predictive for the evolving long-term hormonal disturbances, since pituitary failure may be a dynamic condition in these patients. Periodic evaluations of endocrine function after the first post-injury year may be necessary in a selected subgroup - especially after severe head injury, requirement for neurosurgical interventions, incriminating clinical signs - since pituitary function may change in a considerable proportion of these patients in the long term.

\section{CONFLICT OF INTEREST}

The authors declare that there was no conflict of interest.

\section{REFERENCES}

1. Tagliaferri F, Comapagnone C, Korsic M, Servadei F, Kraus J, 2006 A systematic review of brain injury epidemiology in Europe. Acta Neurochir (Wien) 148: 255-268.

2. Van Baalen B, Odding E, Maas AI, Ribbers GM, Bergen MP, Stam HJ, 2003 Traumatic brain injury: classification of initial severity and determination of functional outcome. Disabil Rehabil 25: 9-18.

3. Benvenga S, Campenni A, Ruggeri RM, Trimarchi F, 2000 Clinical review 113: Hypopituitarism secondary to head trauma. J Clin Endocrinol Metab 85: 1353-1361.

4. Daniel PM, Prichard MM, Treip CS, 1959 Traumatic infarcion of the anterior lobe of the pituitary gland. Lancet 2: 927-931.

5. Aimaretti G, Ambrosio MR, Benvenga S, et al, 2004 Hypopituitarism and growth hormone deficiency (GHD) after traumatic brain injury (TBI). Growth Horm IGF Res 14: Suppl 1: 114-117.

6. Kornblum RN, Fischer RS, 1969 Pituitary lesions in craniocerebral injuries. Arch Pathol 88: 242-248.

7. Crompton MR, 1971 Hypothalamic lesions following closed head injury. Brain 94: 165-172.

8. Popovic V, Pekic S, Pavlovic D, et al, 2004 Hypopituitarism as a consequence of traumatic brain injury (TBI) and its possible relation with cognitive disabilities and mental distress. J Endocrinol Invest 27: 1048-1054.

9. Bavisetty S, Mc Arthur DL, Dusick JR, et al, 2008 Chronic hypopituitarism after traumatic brain injury: risk assessment and relationship to outcome. Neurosurgery 62: 1080-1094.

10. Krahulik D, Zapletalova J, Frysak Z, Vaverka Z, 2010 Dysfunction of hypothalamic-hypophysial axis after TBI in adults. J Neurosurg 113: 581-584.

11. Kelly DF, Gonzalo IT, Cohan P, Berman N, Swerdloff 
R, Wang C, 2000 Hypopituitarism following traumatic brain injury and aneurysmal subarachnoid hemorrhage: a prelimiary report. J Neurosurg 93: 743-752.

12. Lieberman SA, Oberoi AL, Gilkison CR, Masel BE, Urban RJ, 2001 Prevalence of neuroendocrine dysfunction in patients recovering from traumatic brain injury. J Clin Endocrinol Metab 86: 2752-2756.

13. Bondanelli M, De Marinis L, Ambrosio MR, et al, 2004 Occurence of pituitary dysfunction following traumatic brain injury. J Neurotrauma 21: 685-696.

14. Aimaretti G, Ambrosio MR, Di Somma C, et al, 2004 Traumatic brain injury and subarachnoid haemorrhage are conditions at high risk for hypopituitarism: screening study at 3 months after the brain injury. Clin Endocrinol (Oxf) 61: 320-326.

15. Aimaretti G, Ambrosio MR, Di Somma C, et al, 2005 Residual pituitary function after brain injury-induced hypopituitarism: a prospective 12-month study. J Clin Endocrinol Metab 90: 6085-6092.

16. Tanriverdi F, Senyurek H, Unluhizarci K, Selcuklu A, Casanueva FF, Kelestimur F, 2006 High risk of hypopituitarism after traumatic brain injury: a prospective investigation of anterior pituitary function in the acute phase and at 12 months after the trauma. J Clin Endocrionol Metab 91: 2105-2111.

17. Hermann BL, Rehder J, Kahlke S, et al, 2006 Hypopituitarism following severe traumatic brain injury. Exp Clin Endocrinol Diabetes 114: 316-321.

18. Klose M, Juul A, Poulsgaard L, Kosteljanetz M, Brennum J, Feldt-Rasmussen U, 2007 Prevalence and predictive factors of post-traumatic hypopituitarism. Clin Endocrinol (Oxf) 67: 193-201.

19. Leal-Cerro A, Flores JM, Rincon M, et al, 2005 Prevalence of hypopituitarism and growth hormone deficiency in adults long-term after severe traumatic brain injury. Clin Endocrinol (Oxf.) 62: 525-532.

20. Agha A, Rogers B, Sherlock M, et al, 2004 Anterior pituitary dysfunction in survivors of traumatic brain injury. J Clin Endocrinol Metab 89: 4929-4936.

21. Schneider HJ, Schneider M, Saller B, et al, 2006 Prevalence of anterior pituitary insufficiency 3 and 12 months after traumatic brain injury. Eur J Endocrinol 154: 259-265.

22. Schneider HJ, Kreitschmann-Andermahr I, Ghigo E, Stalla GK, Agha A, 2007 Hypothalamopituitary dysfunction following traumatic brain injury and aneurysmal subarachnoid hemorrhage: a systematic review. JAMA 298: 1429-1438.

23. Schneider M, Schneider HJ, Yassouridis A, Saller B, von Rosen F, Stalla GK, 2008 Predictors of anterior pituitary insufficiency after traumatic brain injury. Clin Endocrinol (Oxf) 68: 206-212.

24. Schneider HJ, Samann PG, Schneider M, et al, 2007 Pituitary imaging abnormalities in patients with and without hypopituitarism after traumatic brain injury. $\mathrm{J}$ Endocrinol Invest 30: RC9-RC12.

25. Agha A, Ryan J, Sherlock M, Thompson CJ, 2005 Spontaneous recovery from post-traumatic hypopituitarism. Am J Phys Med Rahabil 84: 381-385.

26. Agha A, Sherlok M, Phililips J, Tormey W, Thompson CJ, 2005 The natural history of post-traumatic neurohypophysial dysfunction. Eur J Endocrinol 152: 371-377.

27. Schneider HJ, Schneider M, Kreitschmann-Andermahr I, et al, 2011 Structured assessment of hypopituitarism after traumatic brain injury and aneurysmal subarachnoid hemorrhage in 1242 patients: the German interdisciplinary database. J Neurotrauma 28: 1693-1698.

28. Secco A, di Lorgi N, Napoli F, et al, 2009 Reassessment of the growth hormone status in young adults in childhood-onset growth hormone deficiency: reappraisal of insulin tolerance testing. J Clin Endocrinol Metab 94: 4195-4204.

29. Murray RD, Adams JE, Shalet SM, 2004 Adults with partial growth hormone deficiency have an adverse body composition. J Clin Endocrinol Metab 89: 1586-1591.

30. Glynn N, Agha A, 2013 Which patients requires neuroendocrine assessment following traumatic brain injury, when and how? Clin Endocrinol (Oxf) 78: 17-20.

31. Ulfarsson T, Gudnaso GA, Rosén T, et al, 2013 Pituitary function and functional outcome in adults after severe traumatic brain injury: the long-term perspective. J Neurotrauma 30: 271-280.

32. Ghigo E, Aimaretti G, Corneli G, 2008 Diagnosis of adult GH deficiency. Growth Horm IGF1 Res 18: 1-16.

33. Blair JC, 2010 Prevalence, natural history and consequences of posttraumatic hypopituitarism:a case for endocrine surveillance. Br J Neurosurg 24: 10-17.

34. Tanriverdi F, Agha A, Aimaretti G, et al, 2011 Manifesto for the current understanding and management of traumatic brain injury-induced hypopituitarism. J Endocrinol Invest 34: 541-543.

35. Tanriverdi F, Taheri S, Ulutabanca H, et al, 2008 Apolipoprotein E3/E3 genotype decreases the risk of pituitary dysfunction after traumatic brain injury due to varios causes: preliminary data. J Neurotrauma 25: 1071-1077.

36. Tanriverdi F, De Bellis A, Bizzarro A, et al, 2008 Antipituitary antibodies after traumatic brain injury: is head trauma-induced pituitary dysfunction associated with autoimmunity? Eur J Endocrinol 159: 7-13.

37. Tanriverdi F, De Bellis A, Battaglia M, et al, 2010 Investigation of antihypothalamus and antipituitary antibodies in amateur boxers: is chronic repetitive head trauma-induced pituitary dysfunction associated with autoimmunity? Eur J Endocrinol 162: 861-867.

38. Kokshoorn NE, Wassenaar MJ, Biermasz NR, et al, 2010 Hypopituitarism following traumatic brain injury: prevalence is affected by the use of different dynamic tests and different normal values. Eur J Endocrinol 162: 11-18. 